\title{
Systematic review of effects of current transtibial prosthetic socket designs_-Part 1: Qualitative outcomes
}

\author{
Mohammad Reza Safari, PhD; ${ }^{{ }^{*}}$ Margrit Regula Meier, $\mathbf{P h D}^{\mathbf{2}}$ \\ ${ }^{1}$ Department of Orthotics and Prosthetics, University of Social Welfare and Rehabilitation Sciences, Tehran, Iran; \\ ${ }^{2}$ Department for Occupational Therapy, Prosthetics, and Orthotics, Faculty of Health Sciences, Oslo and Akershus \\ University College of Applied Sciences, Oslo, Norway
}

\begin{abstract}
This review is an attempt to untangle the complexity of transtibial prosthetic socket fit, determine the most important characteristic for a successful fitting, and perhaps find some indication of whether a particular prosthetic socket type might be best for a given situation. Further, it is intended to provide directions for future research. We followed the PRISMA (Preferred Reporting Items for Systematic Reviews and Meta-Analyses) guidelines and used medical subject headings and standard key words to search for articles in relevant databases. No restrictions were made on study design or type of outcome measure. From the obtained search results $(n=$ $1,863), 35$ articles were included. The relevant data were entered into a predefined data form that incorporated the Downs and Black risk of bias assessment checklist. Results for the qualitative outcomes ( $n=19$ articles) are synthesized. Total surface bearing sockets lead to greater activity levels and satisfaction in active persons with amputation, those with a traumatic cause of amputation, and younger persons with amputation than patellar tendon bearing sockets. Evidence on vacuum-assisted suction and hydrostatic sockets is inadequate, and further studies are much needed. To improve the scientific basis for prescription, comparison of and correlation between mechanical properties of interface material, socket designs, user characteristics, and outcome measures should be conducted and reported in future studies.
\end{abstract}

Key words: amputation, patellar tendon bearing socket, prosthesis, PTB socket, qualitative outcome, socket, total surface bearing socket, transtibial, TSB socket, vacuum-assisted suction socket, VAS socket.

\section{INTRODUCTION}

Prosthetic sockets seem to remain a top priority for people using lower-limb prostheses. In a recent publication, Klute et al. presented needs assessment results of people with a lower-limb amputation [1]. They used a multistakeholder focus group approach to assess priority areas in lower-limb prosthetic care and reported that prosthetic sockets have top priority; users expressed their wish for an adaptable prosthetic socket and suspension system that responds to residual limb changes, heat, and activity. Roughly 15 years ago, similar results were reported by Legro et al. [2]. They analyzed issues of

\footnotetext{
Abbreviations: $\mathrm{ABC}=$ Activity Balance Confidence scale, $\mathrm{ADL}=$ activity of daily living, AMPPro = Amputee Mobility Predictor with Prosthesis, DBS = Downs and Black score, EVA = ethylene vinyl acetate, $\mathrm{HS}=$ hydrostatic, ICEROSS = Icelandic Roll-On Suction Socket, LCI-5 = Locomotor Capabilities Index, $\mathrm{OR}=$ odds ratio, $\mathrm{PEQ}=$ Prosthesis Evaluation Questionnaire, PRISMA $=$ Preferred Reporting Items for Systematic Reviews and Meta-Analyses, PTB = patellar tendon bearing, $\mathrm{QoL}=$ quality of life, $\mathrm{RCT}=$ randomized controlled trial, $\mathrm{SCS}=$ Socket Comfort Score, TSB $=$ total surface bearing, VAS $=$ vacuum-assisted suction, $\mathrm{WoK}=$ Web of Knowledge.

*Address all correspondence to Mohammad Reza Safari, PhD; Department of Orthotics and Prosthetics, University of Social Welfare and Rehabilitation Sciences, Tehran, Iran 1985713834; +98(0)21-2218-0010; fax: +98(0)21-2218-0049. Email: m.r.safari.k@gmail.com
} http://dx.doi.org/10.1682/JRRD.2014.08.0183 
importance to users with lower-limb prostheses, employing two outcome measures: 36-Item Short-Form Health Survey (a multidimensional health status questionnaire) and Prosthesis Evaluation Questionnaire (PEQ), with four out of seven categories addressing aspects of prosthesis function and the remaining three addressing mobility and psychosocial issues. Of the study participants, 92 (roughly 98\%) responded that the fit of the prosthesis was their top issue. More than a decade later, little seems to have changed in terms of user satisfaction in regard to prosthetic sockets and their fit; the subject remains complex and challenging.

A prosthetic socket is designed to fit around a residual limb, serving as a mechanical coupling between the human and artificial limb. It transfers loads under static and dynamic conditions. Therefore, the efficiency of this coupling depends on minimal movement between the residual limb and the prosthesis (i.e., coupling stiffness) [3]. To create a stable connection, the prosthetic socket must provide a snug fit around the residual limb. However, the residual limb is not physiologically designed to tolerate forces and moments applied by the socket. Prosthetists are therefore faced with the challenge of creating a viable interface between a relatively stiff environment (the prosthetic socket) and a surface-changing environment with different and variable properties (the residual limb). It is therefore understandable that the prosthetic socket remains the number one priority for users, because for most of them, wearing comfort depends on socket shape and fit $[2,4-5]$. Poor socket fit will increase the amount of unwanted forces over the residual limb, thus adversely influencing a user's comfort and increasing the experience of pain and tissue breakdown. This could influence the use of a prosthesis as well as the walking pattern of a user, increasing the likelihood of other physical complications and disorders. Activities of daily living (ADLs) and social participation may also be influenced by a poor socket fit, thus decreasing quality of life (QoL) [6].

When focusing on load transfer mechanisms, current prosthetic socket designs for people with transtibial amputation can be categorized into four main groups: (1) patellar tendon bearing (PTB), (2) total surface bearing (TSB), (3) hydrostatic (HS), and (4) vacuum-assisted suction (VAS) sockets. These four main groups also represent the development history of the sockets, shortly described next. According to the PTB principles introduced by Radcliff, the residual limb is loaded proportionally based on gait biomechanics and soft tissue "pressure tolerance limits" [7]. The load is applied to the patellar tendon, anterior medial tibia flare, anterior muscular compartment, and popliteal area while pressure is relieved on the fibular head, anterior tibia crest, and anterior distal tibia. With the introduction of liners made of elastomeric materials, the TSB socket design became available, which claimed to apply pressure more evenly over the entire residual limb than PTB sockets [8]. The effectiveness of TSB sockets relies mainly on the mechanical property of the liner material. HS sockets were introduced later based on Pascal's principle of fluid dynamics; they are made by using a pressure casting method in combination with an elastomeric liner [9]. By contrast, a VAS socket secures the limb within the socket using elevated negative pressure [10]. A first liner is rolled over the residual limb. This liner has similar material characteristics as liners used for TSB and HS sockets and stays in contact with the residual limb due to its snug fit and the adhesion characteristics of the liner's surface [11-12]. The user then steps into the prosthetic socket and pulls an additional rubber-like, open-ended liner over the prosthetic socket and the brim of the first liner, creating a seal. Negative pressure is then applied between the prosthetic socket and the first liner to secure the socket, thus providing an airtight suspension of the prosthesis. VAS sockets increase the rate of fluid drawn into the residual limb, thus minimizing residual limb volume loss [13]. Improved proprioception, walking ability, and residual limb and socket coupling, as well as less pain and lower interface pressure during stance phase, have also been reported in connection with VAS sockets [13-16]. However, a lack of evidence exists to support the absolute indication of effect on satisfaction, comfort, performance, mobility, and gait for these socket designs [17-24].

The effect of prosthetic sockets on people with amputation can be evaluated using quantitative outcomes (e.g., gait analysis, interface pressure measurement) or qualitative outcome measures (e.g., assessments of QoL, ADLs, and/or overall satisfaction). In addition, comparing the cost of prosthetic services with the results of subjective and/or objective outcome measures will assist in the management of prosthetic services in general, including policy making. Further, the ability to solidify core factors that characterize design features of "good" prosthetic sockets will provide direction for future innovations in prosthetic socket design. 
This review is an attempt to untangle the complexity of prosthetic socket fit and perhaps find some indication of whether a particular prosthetic socket type might be best for a given situation. We analyzed whether a combination of various outcome measures showed trends for the strength of a particular socket type in relation to specific outcome measures. We analyzed current evidence of the effect of available prosthetic socket designs on the combined characteristics of qualitative and quantitative outcomes in persons with transtibial amputation. This article represents the first part of this comprehensive review, presenting the results of qualitative outcomes only.

\section{METHODS}

To ensure transparency and comprehensive reporting for systematic reviews, the guidelines and steps suggested in the Preferred Reporting Items for Systematic Reviews and Meta-Analyses (PRISMA) statement were followed [25]. We prespecified the review's rationale and methods in a protocol before the start of the study.

\section{Eligibility Criteria}

The review period was from 1998 to July 2013 (15 years). Both randomized and nonrandomized studies that examined the benefit or harm of PTB, TSB, HS, and VAS sockets were included. Studies for which results were obtained from persons with unilateral or bilateral transtibial amputations due to any cause of amputation and with at least 6 mo of prosthesis experience (i.e., participants having a mature residual limb) were considered. No restrictions were made on the type of outcome measures used. Studies were excluded when no full text was available, when not written in English, and when published before 1998. Letters to editors were also excluded.

\section{Sources of Information and Search}

Studies were identified by searching the following databases: Medline (PubMed) and EMBASE (Ovid Interface). In addition, Google Scholar, the Cochrane Library, and Web of Knowledge (WoK) were also searched. Because the Journal of Prosthetics and Orthotics is not indexed in any of these databases, the "journals@ovid" search was also performed. Both medical subject heading terms (MeSH and EMTREE) and standard key words were used to locate relevant articles. The search strategy was refined for each specific database. The search terms and strategy used for the databases can be found in Appendix 1 (available online only).

\section{Study Selection}

Both authors read the titles and abstracts of the search results and selected relevant studies based on the study eligibility criteria. The authors worked independently to minimize influential bias. In addition, the reference lists of all included studies were checked for possible relevant studies not returned by database searches.

\section{Data Collection Process}

The data extraction table specific to this review was prepared using the Cochrane Data Collection Form for nonrandomized studies [26] (Appendix 2, available online only). The relevant information from the included studies was extracted and data summary tables were generated for each study. Information about study type, objective(s) of the study, participants, inclusion and exclusion criteria, outcome measure, main results, findings, and conclusions were entered. Data were collected by the first author (M.R.S.) and then checked by the second author (M.R.M.).

\section{Assessing Risk of Bias in Selected Studies}

The risk of bias of the included studies was assessed using the checklist created and tested by Downs and Black [27] (Appendix 2, available online only). The checklist provides a scale for assessing the methodological quality of both randomized and nonrandomized studies. The tool is easy to use and has a description for each of its 28 items. The validity and reliability of the Downs and Black tool has been reported to be reasonably high, with the exception of the external validity assessment. In a study evaluating 194 study quality assessment tools, Deeks et al. reported that the Downs and Black checklist is one of the "best" for use in systematic reviews [28].

\section{RESULTS}

The PRISMA flow diagram was used to summarize the study's selection process and reasons for exclusions [25] (Figure).

\section{Study Selection}

After adjusting the results for duplicates, the search of MEDLINE $(n=328)$, EMBASE $(n=349)$, journals@ovid $(n=732)$, Google Scholar $(n=778)$, WoK 

Journals@Ovid (732)
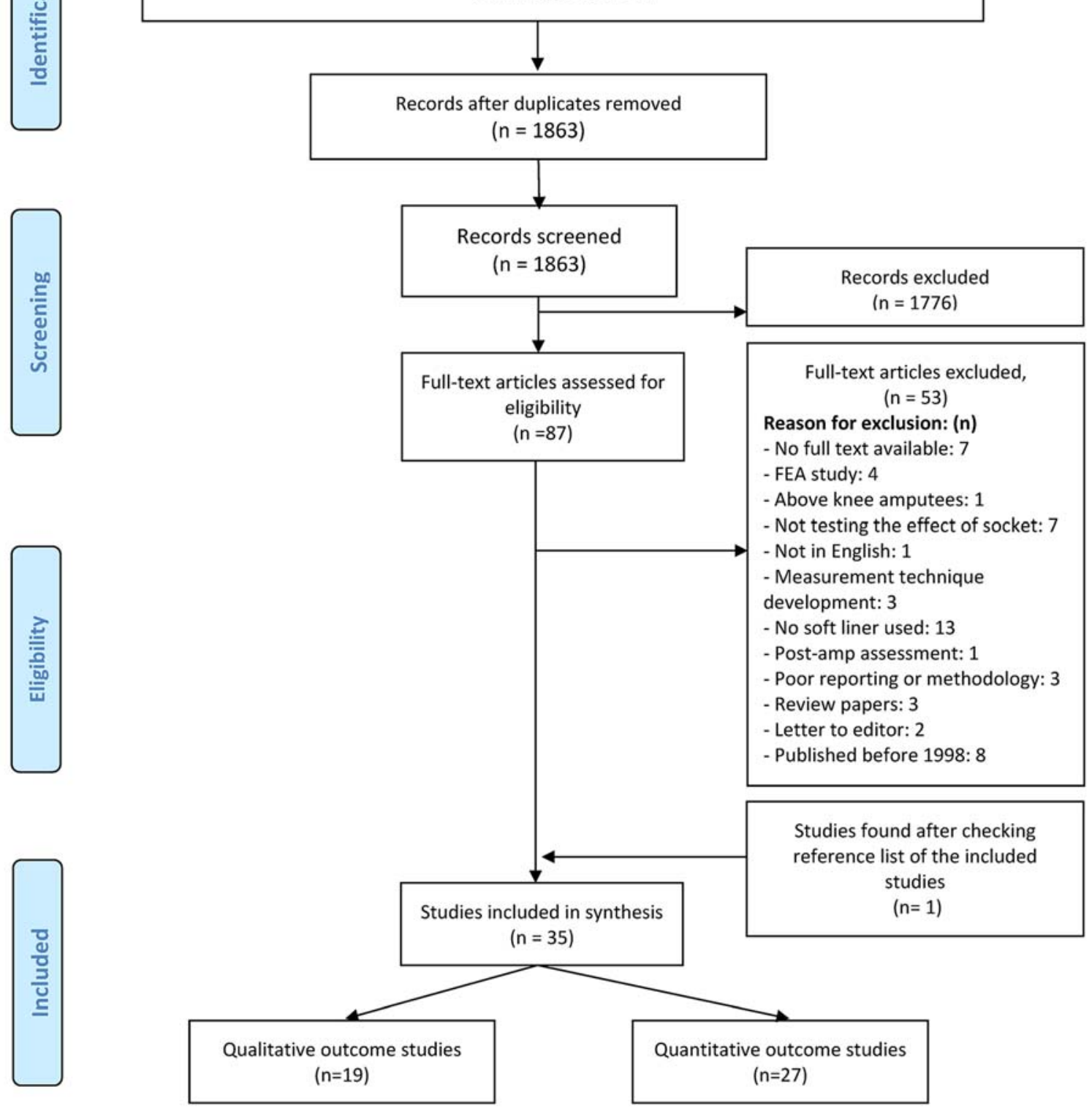

Figure.

Flow diagram of study selection. Amp = amputation, FEA $=$ finite element analysis, WoK $=$ Web of Knowledge.

$(n=504)$, and Cochrane Library $(n=22)$ led to a total of 1,863 articles. After reviewing the titles and/or abstracts of these studies, 1,776 studies were excluded because they did not meet the inclusion criteria. After full-text review of the remaining studies, 53 were further excluded due to various reasons (Figure). One additional article was included after checking the reference lists of the included studies. This resulted in a total of 35 articles considered for full review, with 19 articles that related to qualitative outcomes only.

\section{Study Characteristics}

Tables 1 and 2 present the studies' designs, settings, and Downs and Black scores (DBSs). Appendix 3 (available 
online only) presents the summary data for each included study using the PICOS approach (participants, interventions, comparators, outcomes, and study design).

\section{Methods of Studies}

The methodological designs of the 19 articles that focus on qualitative outcomes and prosthetic socket design varied considerably across studies: crossover designs $(n=5)$ [29-33], randomized crossover designs $(n=3)$ [24,34-35], and cross-sectional designs $(n=3)$ [36-38] were the most frequent study methods used. The remaining studies included case report or single-subject design $(n=2)$ [39-40], case-series design $(n=1)$ [41], survey $(n=1)$ [21], randomized controlled trial (RCT) $(n=2)$ [23], controlled trial $(n=1)$ [42], and prospective study design $(n=1)$ [43] (Table 1).

\section{Participants}

A total of 790 adults with amputation, with an average age of $50.7 \mathrm{yr}$, participated in the included studies. Studies that reported the sex of participants showed that the majority were male (male: 592 vs female: 151). Most study participants were amputated due to trauma $(n=$ 513). The cause of amputation for 178 participants was vascular insufficiency or diabetes, and 99 were amputated due to causes other than trauma, diabetes, or vascular insufficiency.

\section{Intervention}

The following socket types were used in the studies. The TSB socket was used in eight studies, of which one used the TSB socket only in combination with a silicone liner. Seven of the eight studies compared the effects of liner material, of which six analyzed the suspension provided by liners (Seal-In versus sleeve suspension [1 study] and pin lock versus Seal-In [4 studies]), one compared silicone with urethane liners, and one compared different liner thicknesses (3 vs $6 \mathrm{~mm}$ ).

Five studies compared PTB and TSB sockets. The type of suspension for PTB sockets was not reported; however, the TSB sockets were used with either Dermo pin lock and Seal-In liners $(n=1)$, Alpha liners $(n=1)$, laminated silicone liners ${ }^{*}(n=1)$, or silicon or urethane

* In order to achieve a TSB socket with a silicone liner, the prosthetist in the reported study fabricated a soft inner socket by laminating a silicone resin over the positive plaster model of the residual limb.

Table 1.

Study designs and settings.

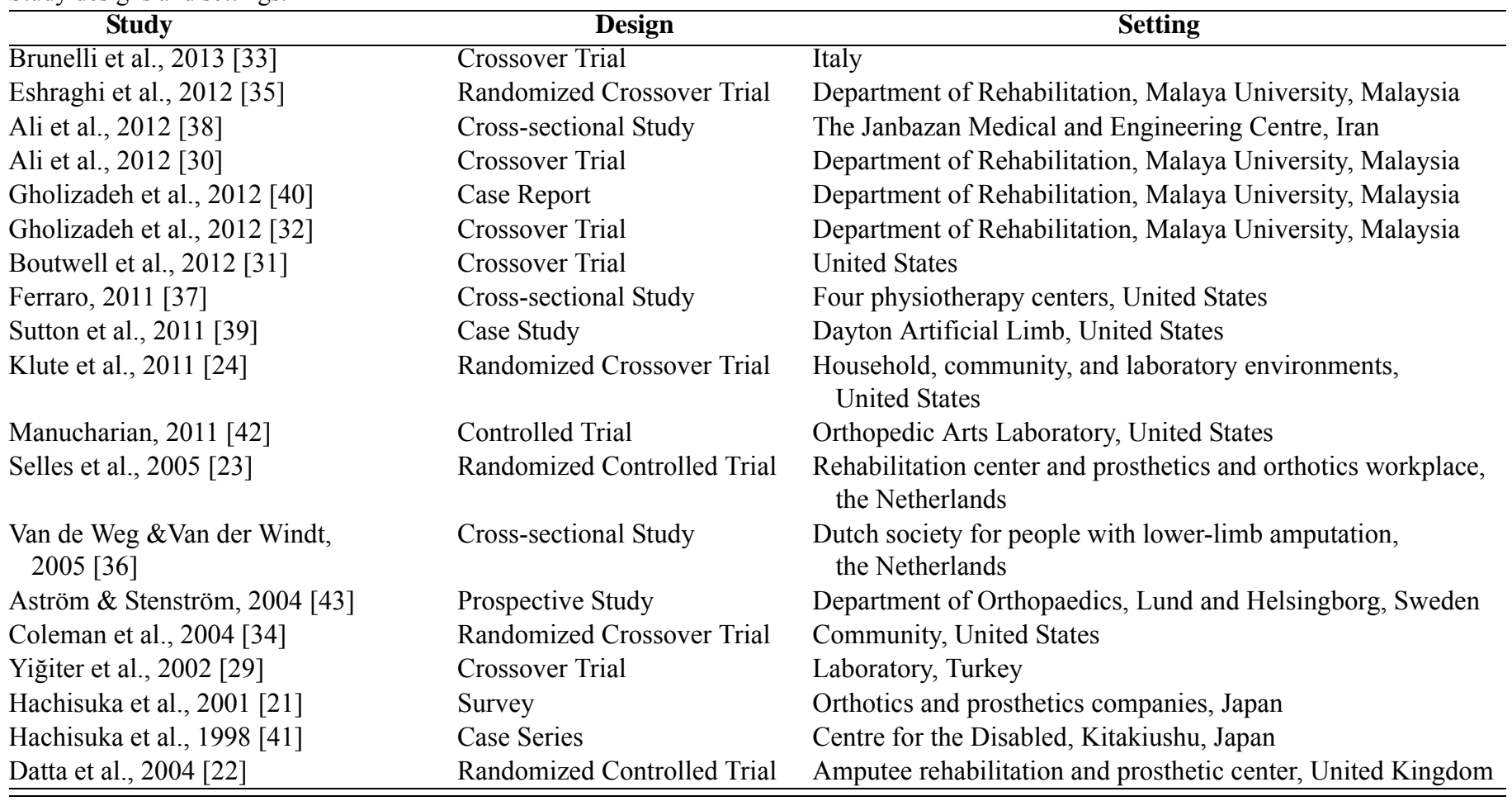


liners $(n=1)$. One study did not report the type of liner used for the TSB sockets.

VAS sockets were used in three studies, where one examined the effects of VAS sockets only and the other two compared VAS sockets with TSB sockets with pin lock liners. However, no information was provided for the liner type used in the VAS sockets.

Three studies compared HS sockets with either PTB or TSB sockets. Two studies used the Icex HS socket. One compared it with TSB sockets with Comfort or Two Color liners and the other one compared it with PTB sockets with Pelite liners. The third study used the PTB socket with sleeve suspension and compared it with Hydrocast HS sockets with Pelite liners.

Differences existed in the acclimation times given to the participants, ranging from $1 \mathrm{wk}$ to more than $20 \mathrm{yr}$. In three studies, the acclimation period of the test prosthesis was not reported. Seven studies adopted a socket adaptation time of less than $3 \mathrm{mo}$, and in four studies, participants used their study prosthesis for 3 mo or longer. In the remaining studies $(n=5)$, the wearing time was not consistent for participants, i.e., varied from less than 3 mo to 3 mo or longer.

\section{Outcomes}

Because the type of outcome measures used within the studies was not considered a selection criteria, the review identified 14 categories of outcome measures, of which 5 were qualitative. They include (1) activity and function, (2) prosthesis- and residual limb-related complications, (3) comfort and pain, (4) satisfaction and preference, and (5) QoL.

\section{Risk of Bias Within Studies}

The maximum DBS is 32 . For ease of analyzing the results based on the level of evidence, we divided the maximum DBS into four equally strong evidence categories: "insufficient" (DBS 0-7), "weak" (DBS 8-15), "moderate" (DBS 16-23), and "robust" (DBS 24-32) [44]. We excluded studies with a DBS from 0 to 7 . The 19 articles included in this review were categorized as follows: 4 as weak, 14 as moderate, and 1 as robust (Table 2).

\section{Syntheses of Results}

A meta-analysis of the results was not possible because the included studies varied too greatly in their methodological design, intervention, participants, and outcome measures. Therefore, a qualitative synthesis of

Table 2.

Risk of bias within included studies using Downs and Black score (DBS). For description of score items, see Appendix 2 (available online only).

\begin{tabular}{|c|c|c|c|c|c|c|c|c|c|c|c|c|c|c|c|}
\hline \multirow{2}{*}{ Study } & \multicolumn{11}{|c|}{ Reporting } & \multicolumn{4}{|c|}{ External Validity } \\
\hline & R1 & $\mathbf{R} 2$ & R3 & R4 & R5 & R6 & R7 & $\mathbf{R 8}$ & R9 & R10 & SS & EV1 & EV2 & EV3 & SS \\
\hline Brunelli et al., 2013 [33] & 1 & 1 & 1 & 1 & 1 & 1 & 1 & 1 & 1 & 1 & 10 & 0 & 0 & 0 & 0 \\
\hline Eshraghi et al., 2012 [35] & 1 & 1 & 1 & 1 & 1 & 1 & 1 & 1 & 1 & 1 & 10 & 0 & 0 & 0 & 0 \\
\hline Ali et al., 2012 [38] & 1 & 1 & 1 & 1 & 0 & 0 & 0 & 1 & 0 & 0 & 5 & 0 & 0 & 1 & 1 \\
\hline Ali et al., 2012 [30] & 1 & 1 & 1 & 1 & 1 & 1 & 1 & 1 & 1 & 1 & 10 & 0 & 0 & 0 & 0 \\
\hline Gholizadeh et al., 2012 [40] & 1 & 0 & 1 & 1 & 0 & 1 & 0 & 0 & 0 & 0 & 4 & 0 & 0 & 1 & 1 \\
\hline Gholizadeh et al., 2012 [32] & 1 & 1 & 1 & 1 & 1 & 1 & 1 & 1 & 1 & 1 & 10 & 0 & 0 & 0 & 0 \\
\hline Boutwell et al., 2012 [31] & 1 & 1 & 1 & 1 & 1 & 1 & 1 & 1 & 1 & 1 & 10 & 0 & 0 & 1 & 1 \\
\hline Ferraro, $2011[37]$ & 1 & 1 & 0 & 1 & 1 & 1 & 1 & 0 & 0 & 1 & 7 & 0 & 0 & 1 & 1 \\
\hline Sutton et al., 2011 [39] & 1 & 1 & 1 & 1 & 1 & 1 & 0 & 1 & 1 & 0 & 8 & 0 & 0 & 1 & 1 \\
\hline Klute et al., 2011 [24] & 1 & 1 & 1 & 1 & 1 & 1 & 1 & 1 & 1 & 1 & 10 & 1 & 0 & 1 & 2 \\
\hline Manucharian, 2011 [42] & 1 & 1 & 1 & 1 & 1 & 1 & 1 & 0 & 1 & 1 & 9 & 0 & 0 & 0 & 0 \\
\hline Selles et al., 2005 [23] & 1 & 1 & 1 & 1 & 1 & 1 & 1 & 1 & 1 & 1 & 10 & 0 & 0 & 1 & 1 \\
\hline Van de Weg \& Van der Windt, 2005 [36] & 1 & 1 & 1 & 0 & 1 & 1 & 1 & 1 & 0 & 1 & 8 & 1 & 0 & 1 & 2 \\
\hline Aström \& Stenström, 2004 [43] & 1 & 1 & 1 & 0 & 0 & 0 & 0 & 1 & 1 & 0 & 5 & 1 & 1 & 1 & 3 \\
\hline Coleman et al., 2004 [34] & 1 & 1 & 1 & 1 & 1 & 1 & 1 & 1 & 1 & 1 & 10 & 0 & 0 & 1 & 1 \\
\hline Yiğiter et al., 2002 [29] & 1 & 1 & 1 & 1 & 1 & 1 & 1 & 0 & 1 & 0 & 8 & 0 & 0 & 0 & 0 \\
\hline Hachisuka et al., 2001 [21] & 1 & 1 & 1 & 1 & 1 & 1 & 0 & 0 & 0 & 0 & 6 & 1 & 1 & 1 & 3 \\
\hline Hachisuka et al., 1998 [41] & 1 & 1 & 1 & 1 & 1 & 1 & 1 & 1 & 1 & 0 & 9 & 0 & 0 & 1 & 1 \\
\hline Datta et al., 2004 [22] & 1 & 1 & 1 & 1 & 1 & 1 & 1 & 0 & 1 & 1 & 9 & 0 & 0 & 1 & 1 \\
\hline
\end{tabular}


the results was performed. The results are listed in relation to the five categories identified previously, categorized according to socket type and ranked within each section in accordance to level of evidence.

\section{Activity and Function}

Eight studies reported activity, function, and mobility of participants in regard to TSB, HS, VAS, and PTB sockets. One study was scored as having robust evidence [23], four as having moderate evidence [24,29,33-34], and three as having weak evidence $[37,39,43]$. The majority of these studies used patient-reported outcome measures to report activity and function, with only a few listing quantitative instruments. Since the majority of the studies used qualitative measures, we decided to include the results of the few studies using quantitative instruments here to complete the analysis.

TSB. Moderate evidence - Based on a crossover trial by Brunelli et al. (DBS 22), the score for the ambulation section of the PEQ was significantly higher for people using a TSB socket with a Seal-In liner than with sleeve suspension (88 vs 79) [33]. Furthermore, the Houghton Scale Questionnaire score for items such as duration of prosthesis use, manner in which prosthesis was used, per- ceptions of stability, and use of walking aids was significantly higher for TSB sockets with a Seal-In liner. However, no significant differences were found between the two socket systems in the "Timed Up and Go" test and Locomotor Capabilities Index (LCI-5) score of ability to perform motor tasks.

Weak evidence-In a prospective study by Aström and Stenström (DBS 15), participants used their new prosthesis with a TSB socket and a polyurethane liner [43]. Out of 29 participants, 20 had residual limb problems, with 18 claiming pain as a limiting factor for ambulation. By switching to the new prosthesis, 67 percent rated it as being better or much better for physical activity than their previous prostheses (Icelandic Roll-On Suction Socket [ICEROSS], $n=18$; ethylene vinyl acetate (EVA), $n=9$; or suction socket, $n=2$ ), while 9 percent reported their previous socket to be better or much better. Sixteen percent did not report any differences between the new and old prosthesis socket.

PTB versus TSB. Moderate evidence-In a randomized crossover trial by Coleman et al. (DBS 22), study participants were given both a TSB socket with an Alpha liner (a mineral oil-based elastomeric liner) and a PTB

Table 2. (cont)

Risk of bias within included studies using Downs and Black score (DBS). For description of score items, see Appendix 2 (available online only).

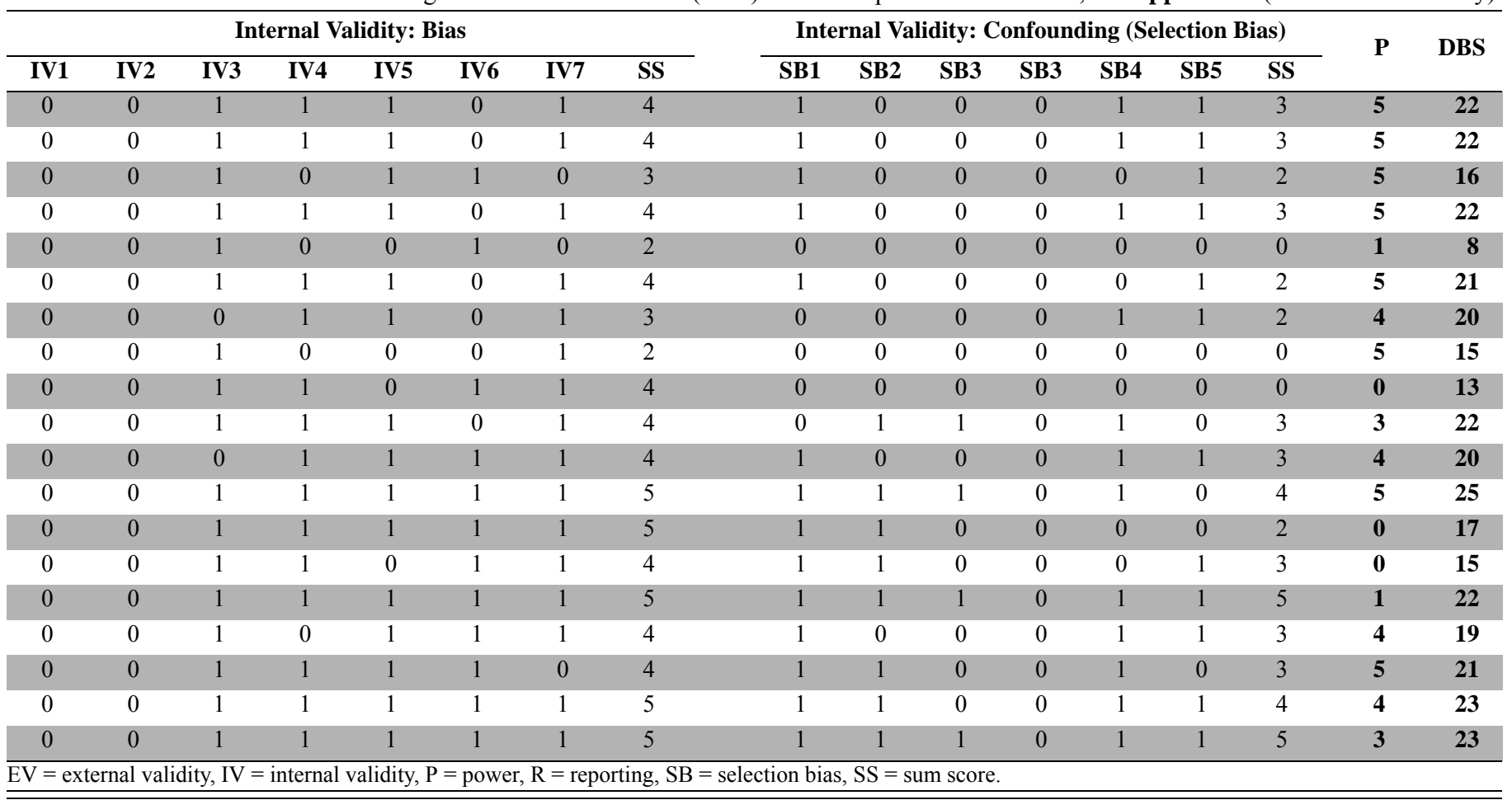


socket to use for 3 mo each [34]. Results from step activity monitoring indicated that participants spent 82 percent more hours per day and took 83 percent more steps per day in the PTB socket. Participants wore the PTB socket more full days than the TSB socket. This could be the reason why higher activity levels were recorded and a greater numbers of steps were counted with the PTB socket. In days where sockets were worn, comparisons between the PTB and TSB sockets revealed that participants spent 72 percent more time in high-intensity activities and took 49 percent more steps per day with a PTB socket. However, during the time participants were active in each socket, the intensity distribution was not significantly different between sockets. The PEQ score for "ambulation" was not significantly different between PTB (mean \pm standard deviation: 78.6 \pm 17.5 ) and TSB $(71.6 \pm 24)$ sockets. In an open-ended feedback section, participants reported that performance with a PTB socket was not as good for some activities and not as bad for others, but a combination of features were given that seem to make the PTB socket more versatile for daily use, whereas the TSB socket was preferred for some activities but not for others. Coleman et al. noted that the baseline distribution was not equal and the number of subjects was too small to draw a conclusion toward the previous prosthetic experience.

In a crossover trial, Yiğiter et al. (DBS 19) reported that the time for ascending and descending 10 steps and an incline was significantly shorter when participants used a TSB socket than a PTB socket, but no significant difference between the two sockets was found in time required for crossing obstacles [29]. The type of liner used for TSB sockets was not mentioned for this study.

PTB versus VAS. Weak evidence-Sutton et al. (DBS 13) assessed the long-term functional capability of one participant (K3 activity level) after he changed from a PTB socket with ischial weight-bearing features to a VAS socket [39]. They reported that the scores of locomotor capability (LCI-5) and ADL were 56 and 8, respectively, after $1 \mathrm{wk}$ of prosthetic use, indicating high functional capabilities. The scores did not change after 1 mo or $1 \mathrm{yr}$ of use with the VAS socket. However, the Amputee Mobility Predictor with Prosthesis (AMPPro) score improved from 1 mo to $1 \mathrm{yr}$ of use from 44 to 48 points. Sutton et al. indicated that the higher AMPPro score suggests an improvement in balance task performances and therefore could be an indicator for improved proprioception. After 1 wk of VAS socket use, in which the participant used his prosthesis for at least $6 \mathrm{~h} / \mathrm{d}$, he reported adequate knee stability, no irritation or discoloration, and no longer any pain in the contralateral limb. After $1 \mathrm{mo}$, the prosthesis was used $10 \mathrm{~h} / \mathrm{d}$ and the participant walked at least $6 \mathrm{mi} / \mathrm{d}$. The participant reported improved prosthesis linkage and no swelling or pain in the contralateral limb. A better gait symmetry was observed by the clinician. Results now suggested a K4 level activity. After $1 \mathrm{yr}$, the participant used the VAS socket occasionally $24 \mathrm{~h} / \mathrm{d}$, hair regrowth was observed, and he expressed confidence in stability at work. He reported no pain but was still unable to stand unsupported on his prosthetic limb.

TSB versus HS. Robust evidence- - In an RCT using activity monitors, Selles et al. (DBS 25) reported that the HS Icex socket was no different from the TSB socket in any variables measured, including time spent in dynamic activities, time spent walking, number of walking periods, number of body posture transitions, and overall mobility [23]. Furthermore, the score for the ambulation section of the PEQ was not significantly different between the two sockets.

TSB versus VAS. Moderate evidence-In a randomized crossover trial, Klute et al. (DBS 22) compared the activity levels of participants when wearing either a VAS socket or TSB socket with pin lock liner [24]. Results were obtained using a step counter over a period of at least $2 \mathrm{wk}$ and showed that participants were twice as active when using TSB sockets than when using VAS sockets $(73,000 \pm 18,000$ steps and 38,000 $\pm 9,000$ steps, respectively). In addition, although not statistically tested, the scores on the ambulation section of the PEQ were higher for the TSB socket $(95 \pm 6)$ than the VAS socket $(67 \pm 22)$.

Weak evidence-In a cross-sectional study conducted by Ferraro (DBS 15), participants reported a reduced fear of falling during ADLs when using the VAS socket than when using their previous TSB socket with pin lock system [37]. The Activity Balance Confidence scale (ABC) scores $80 \pm 10$ and $65 \pm 20$ in VAS socket and TSB socket with pin lock system, respectively. A higher score on the ABC for VAS socket correlates to the lower possibility of future falls. Ferraro reasoned that this could be due to the better socket fit of the VAS system, with less pistoning, a more secure hold and, perhaps, improved proprioception. 


\section{Prosthesis- and Residual Limb-Related Complications}

Thirteen studies reported results relating to outcomes of prosthetic sockets and complications of the residual limb. Among these, 1 study was classified as having robust evidence [23], 11 as having moderate evidence $[21,24,29-30,32-36,38,41]$, and 1 as having weak evidence [43].

TSB. Moderate evidence-Hachisuka et al. (DBS 23) analyzed advantages and disadvantages of TSB sockets and their effect on clinical implications [41]. Based on their case series, perspiration, odor, and staining of the silicone liner incorporating a laminated silicone liner with a pin lock system were regarded as "poor" or "somewhat poor" by more than 20 percent of participants and "good" or "somewhat good" by less than 40 percent. The appearance of the TSB socket, durability, and skin irritation were regarded as "good" or "somewhat good" by more than 75 percent of participants. However, donning and doffing were significantly related to "dissatisfied" and "somewhat dissatisfied" and were considered the main disadvantage of the TSB socket. Hachisuka et al. (DBS 21) followed up on their results in a later study and sent a questionnaire with hygiene-related questions to participants $(n=83)$ who had used a TSB socket with silicone liner for an average of $2.9 \pm 1.5 \mathrm{yr}$ [21]. They reported that participants experienced perspiration $(47 \%)$, eruption $(46 \%)$, itching $(60 \%)$, and odor $(43 \%)$. Perspiration had a direct relationship to hours of prosthetic use (odds ratio $[\mathrm{OR}]=2.01$ ) and was reported to be less prominent in women than men $(\mathrm{OR}=0.10)$. Skin eruption increased in relation to age $(\mathrm{OR}=1.11)$, but washing the liner decreased the probability of eruption $(\mathrm{OR}=0.28)$. Itching decreased with age and the hours of prosthetic use; however, its probability increased with increased intensity of ADLs $(\mathrm{OR}=8.65)$. Odor also decreased with age.

Four crossover trials dealt with the effect of the suspension provided by different socket liners. Gholizadeh et al. (DBS 21) reported that participants significantly experienced fewer noise problems with TSB sockets in combination with Seal-In suction liners than with Dermo liners and pin lock systems (PEQ score: 74.85 vs 95.50) [32]. The use of Dermo liners, however, resulted in more satisfaction with donning and doffing (PEQ score: 87.5 vs 35.44). In addition, differences were reported between the two liners in terms of sweating, sores, odor, swelling, and irritation, but these differences did not reach significant levels. However, Ali et al. (DBS 22) stated that par- ticipants experienced significantly fewer irritation, sores, swelling, and odor problems with the Dermo liner [30]. Although participants reported significantly fewer overall problems with Seal-In liners than Dermo liners (overall PEQ score: 83.0 vs 79.2), the problem with sweat was not significantly different between the two socket types, thus supporting the results from Gholizadeh et al.'s study. Based on a study by Eshraghi et al. (DBS 22), participants indicated fewer problems with sweating, sores, skin irritation, swelling, odor, and noise with the TSB socket and a Seal-In liner than either a magnetic liner or a Dermo pin lock liner; sweating, swelling, and noise were significantly less when wearing the magnetic liner than the Dermo liner [35]. Satisfaction with donning and doffing was rated significantly higher with the Seal-In liner, followed by the magnetic liner and then the Dermo liner. Brunelli et al. (DBS 22) showed that there was no significant difference between a TSB socket with a Seal-In liner and a TSB socket with sleeve suspension when analyzing the scores from the PEQ, except for appearance, which favored the Seal-In liner [33]. The inconsistencies in the findings of these studies could perhaps be explained by short study durations. An accommodation period of 4 wk was reported by Gholizadeh et al. [32], Ali et al. [30], and Eshraghi et al. [35], which, based on clinical experiences, seems to be a relatively short period of time for a user to adapt to a TSB socket.

Weak evidence-In a prospective study by Aström and Stenström (DBS 15), 52 percent of participants reported "better" or "much better" ease of donning with their new TSB socket incorporating a polyurethane liner than with their previous socket (ICEROSS, VAS, or EVA), while 41 percent reported "better" or "much better" ease of donning with their previous socket [43].

PTB versus TSB. Moderate evidence-Based on a randomized crossover trial conducted by Coleman et al. (DBS 22), there was no significant difference between a TSB socket with a mineral oil-based elastomeric liner and a PTB socket with a Pelite liner when analyzing PEQ scores [34]. However, in the open-ended feedback section, study participants reported that skin irritation, perspiration, and prosthesis durability were less of a concern with the PTB socket. They considered donning of the TSB socket to be difficult and time consuming and the maintenance, prosthetic care, and hygiene to be burdensome. Similar results were reported in a cross-sectional study by Van de Weg and Van der Windt (DBS 17) in which three different suspension systems were investigated: PTB 
sockets with Pelite liner $(n=62)$, TSB sockets with silicone liner $(n=94)$, and TSB sockets with polyurethane liner $(n=62)$ [36]. They reported that there was not a significant difference between the three socket suspension systems in either the sum score of perceived problems (a section of the PEQ) or in any individual items such as problems with odor, skin rashes, blisters, pimples, noise, swelling, satisfaction with the look of the prosthesis, and donning and doffing. Although not significant, the two types of TSB sockets were associated with fewer problems than the PTB socket. Interestingly, more sweating was reported when wearing the PTB socket with Pelite liner (36\%) than the TSB socket with silicone liner (21\%) or polyurethane liner $(24 \%)$. The daily maintenance time was considered to be significantly longer for the two TSB sockets than for the PTB socket. Also, more recent studies state similar results. In a survey conducted by Ali et al. (DBS 16), participants reported that wearing a TSB socket combined with a Seal-In liner creates significantly fewer problems with items such as skin irritation, sores, pistoning, rotation of the socket, inflation, odor, pain, and noise than wearing a TSB socket with pin lock liner or PTB socket with a Pelite liner [38]. Compared with the PTB socket, sores, irritation, pistoning, and odor were also significantly less of a problem in the TSB socket with pin and lock system. However, socket rotation and residual limb inflation were significantly less problematic in the PTB socket than the TSB socket. There was also a significant difference between the three suspension systems in regard to maintenance time: the pin lock system required the longest maintenance time $(2.98 \pm 2.63 \mathrm{~h} / \mathrm{yr})$ followed by the Seal-In liner $(2.53 \pm 1.52 \mathrm{~h} / \mathrm{yr})$, while the Pelite liner required the least maintenance time $(0.54 \pm 0.45 \mathrm{~h} / \mathrm{yr})$. Contrary to the results of Coleman et al. [34] and Van de Weg and Van der Windt et al. [36], Yiğiter et al. (DBS 19) reported that the time for donning and doffing a TSB socket was shorter than for a PTB socket [29]. However, the type of liner used, which may have had an influence on the results obtained, was not mentioned in the study.

TSB versus HS. Robust evidence-Selles et al. (DBS 25) conducted an RCT and reported that the HS Icex socket was not different from the TSB socket with silicone liner when analyzing the overall PEQ score or prosthetic-related items of the PEQ such as transpiration, odor, residual limb swelling, and skin problems [23].

TSB versus VAS. Moderate evidence-In a randomized crossover trial, Klute et al. (DBS 22) compared VAS sockets with TSB sockets with Alpha Spirit pin lock lin- ers [24]. Participants expressed that their residual limb was healthier (PEQ score: $90 \pm 5$ vs $77 \pm 20$ ) and that they experienced less frustration (PEQ score: $91 \pm 11$ vs $43 \pm 29$ ) while using the TSB pin lock system compared with the VAS socket.

\section{Comfort and Pain}

Eleven studies reported the participants' perceived residual limb pain and comfort of using prosthesis in relation to TSB, HS, and PTB sockets. Following assessment of study bias, one study was scored as having robust evidence [23], nine as having moderate evidence $[22,30,32,34-36,38,41-42]$, and one as having weak evidence [43].

TSB. Moderate evidence-In a case series, Hachisuka et al. (DBS 23) reported that more than 75 percent of their study participants $(n=32)$ expressed pain during walking but reported comfort wearing the prosthesis to be "good" or "somewhat good" with a TSB socket with laminated silicone liner [41]. Participants' opinions about their previous PTB socket were not reported.

Three studies reported the difference between the types of suspension provided by the liners used in the TSB socket. Based on a crossover trial by Gholizadeh et al. (DBS 21), participants reported fewer pain-related problems with a TSB socket with Seal-In liner than a TSB socket with a pin lock liner (Dermo liner) [32]. In a randomized crossover trial by Eshraghi et al. (DBS 22), participants expressed fewer pain-related problems with a TSB socket with distal magnetic lock liner than with Seal-in liner or pin lock liner [35]. Participants experienced less pain with a Seal-In liner than the pin lock system. However, based on a crossover trial by Ali et al. (DBS 22), participants reported more pain-related problems with a TSB socket in combination with a Seal-In liner than with a pin lock liner (Dermo liner) [30]. The authors stated that more pressure and liner tightness at the middle region of the socket triggered by the five seals of the Seal-In liner could be a reason for this difference.

Weak evidence-Based on a prospective study by Aström and Stenström (DBS 15), 82 percent of study participants reported "better" or "much better" comfort with their new TSB prosthesis incorporating a polyurethane liner than with their previous socket (ICEROSS, suction, or EVA socket), while 6 percent reported "better" or "much better" comfort with their previous socket [43]. The Socket Comfort Score (SCS) was not different between the old and new prostheses in 12 percent of par- 
ticipants. Note that 69 percent of participants ( 20 out of a total of 29 people) had residual limb problems before they switched to the new prosthesis. Eighteen participants mentioned pain as a limiting factor for ambulation. The results reported in Aström and Stenström were presented with descriptive statistics only.

PTB versus TSB. Moderate evidence-According to a randomized crossover trial by Coleman et al. (DBS 22), participants scored a higher SCS when using a PTB socket with Pelite liner $(7.23 \pm 2.5)$ than when using a TSB socket with a mineral-oil-based elastomeric liner $(6.84 \pm 3)$, but the difference was not significant [34]. Furthermore, there was no difference between the two sockets in participants' experiences of pain. In an openended feedback section, participants expressed that the TSB socket comfort was good for a short period of time but that comfort reduces over time [34,38]. Based on the results of a cross-sectional study, Van de Weg and Van der Windt (DBS 17) stated that there was no significant difference in pain experience for participants wearing the PTB socket with Pelite liner $(n=62)$, TSB socket with silicone liner $(n=94)$, or TSB socket with polyurethane liner $(n=64)$ [36]. However, Ali et al. (DBS 16) reported in a cross-sectional study that participants had fewer pain-related problems with a TSB socket with Seal-In liner (PEQ score: 92.67) than either a TSB socket with pin lock liner (PEQ score: 80.62) or a PTB socket with a Pelite liner (PEQ score: 81.18) [38].

PTB versus HS. Moderate evidence-Datta et al. (DBS 23) reported that participants expressed higher SCSs for their Icex HS (mean: 8.2, range: 6-10) than for their previous PTB socket (mean: 7.2, range: 5-9) [22]. However, the statistical significance of the difference was not tested. In a controlled trial, Manucharian (DBS 20) compared participants' SCS trends at initial fitting and after 1 mo follow-up in regard to PTB and HS sockets, both incorporating a soft Pelite liner [42]. The SCS in the HS socket group significantly decreased after 1 mo (difference: $-1.13 \pm 0.65$ ), while the PTB socket users did not show a difference in SCS between initial and final values (difference: $0.09 \pm 0.54$ ). Furthermore, Manucharian reported that SCS was higher for participants who were given a socket not different from their previous. It is worth noting that a Pelite liner was used in both sockets, although the use of such liners in an HS socket is not common practice. Further, the author used a water tank to shape the plaster cast over the residual limb, which again, is not common practice when creating a HS type socket.
TSB versus HS. Robust evidence-Selles et al. (DBS 25) state the results from an RCT and reported that participants' pain and phantom pain were not significantly different between an Icex HS socket and a TSB socket with either a comfort liner or two-color liner* [23]. All liners had pin lock systems.

\section{Satisfaction and Preference}

Eleven studies reported participants' satisfaction and preference with their prosthesis, from which one study was scored as having robust evidence [23], nine as having moderate evidence [29-32,34-36,38,41], and one as having weak evidence [43].

TSB. Moderate evidence-A crossover trial by Boutwell et al. (DBS 20) reported that participants with bony residual limbs preferred using a TSB socket with a $9 \mathrm{~mm}$ thermoplastic elastomer liner despite no improvements in gait characteristics [31]. The authors stated that this may be a result of decreased pressure over bony prominences. However, participants with padded residual limbs expressed a mixed preference toward either liner thickness. The authors indicated that, compared with participants with bony residual limbs, other factors such as weight of the liner and the perceived compliance of the socket and limb may have been influential for participants with padded residual limbs in deciding which liner to choose.

Three crossover trials reported participant satisfaction with different liner suspension all used in combination with a TSB socket. Ali et al. (DBS 22) reported that participants were most satisfied with the TSB socket with Dermo liner for prosthesis fit, level walking, and walking on uneven terrain [30], while Gholizadeh et al. (DBS 21) stated that the TSB socket with Seal-In liner resulted in more satisfaction in participants for these items [32]. Both studies reported that satisfaction with stair ascending and descending and cosmesis of the prosthesis was not significantly different between the two liners tested. Eshraghi et al. (DBS 22) stated that satisfaction with prosthetic fit, sitting, and walking on uneven terrain was higher for Seal-In liners, but while walking on level terrain, participants were more satisfied with a TSB socket with Dermo liner than a TSB socket with Seal-In liner [35]. Eshraghi et al. also stated that the TSB socket with

\footnotetext{
*A pin lock silicone liner with a distal stabilizing matrix, with or without a covering fabric. Stabilizing matrix is stated to minimize pistoning.
} 
distal magnetic liner provided the least prosthetic fit satisfaction, whereas satisfaction with level walking and walking on uneven terrain was highest with a TSB socket with magnetic liner. All three studies reported that participants rated the overall satisfaction with the TSB socket with Dermo liner significantly higher than with the TSB socket with Seal-In liner. However, Eshraghi et al. stated that a TSB socket with distal magnetic liner resulted in more overall satisfaction than the TSB socket with Dermo liner. Note that relatively short acclimation periods of $4 \mathrm{wk}$ were adopted by these studies.

Weak evidence-In a prospective study, Aström and Stenström (DBS 15) interviewed participants about their view on their new TSB socket incorporating a polyurethane liner compared with their old prosthesis with either an ICEROSS, VAS, or EVA socket [43]. After $3 \mathrm{yr}, 20$ out of 24 participants, and after $5 \mathrm{yr}, 19$ out of 20 participants still used the polyurethane liner and expressed that it was the best they had been using. Participant comfort increased considerably and physical activity improved after changing to the polyurethane liner, with improvements remaining throughout the tested $5 \mathrm{yr}$.

PTB versus TSB. Moderate evidence-In a case series by Hachisuka et al. (DBS 23), 16 (50\%) participants were "satisfied" and $8(25 \%)$ were "somewhat satisfied" with the TSB socket with laminated silicone liner [41]. Two (6\%) participants were "dissatisfied" with the TSB socket and decided to go back to the PTB socket, and two $(6 \%)$ were "somewhat dissatisfied" with the TSB socket. A subgroup of nine participants used both sockets during a 2 mo testing period. All reported being either "satisfied" or "somewhat satisfied" with the TSB socket and all decided to use the TSB socket as their chosen socket at the end of the study. The authors reported that comfort to wear, ease to swing the limb, and pistoning were significantly related to overall "satisfied" or "somewhat satisfied." These items were regarded as the advantages of the TSB socket. Donning and doffing was significantly related to "dissatisfied" and "somewhat dissatisfied" and was thus considered to be the disadvantage of the TSB socket. Complaints of odor, staining, and perspiration did not affect the overall satisfaction or dissatisfaction of the TSB socket.

In a randomized crossover trial by Coleman et al. (DBS 22), participants were given both a TSB socket with mineral-oil-based elastomeric liner and a PTB socket with Pelite liner [34]. After using each socket for 3 mo, 10 (out of 13) participants preferred the PTB socket as their only socket of choice. In contrast, Yiğiter et al. (DBS 19) reported that 75 percent (15 out of 20) participants chose a TSB socket over a PTB socket at the end of the study [29]. Unfortunately, the type of liner used with the sockets was not mentioned.

In a cross-sectional study by Van de Weg and Van der Windt (DBS 17), there was no significant difference reported in the overall satisfaction score of participants wearing a PTB socket with Pelite liner $(n=62)$, a TSB socket with silicone liner $(n=94)$, or a TSB socket with polyurethane liner $(n=62)$ [36]. Further, no significant differences were found in the scores for satisfaction of the PEQ except for walking on uneven terrain and sitting, which were rated in favor of the PTB socket. However, in a survey by Ali et al. (DBS 16), participants rated the overall satisfaction with the TSB socket with Seal-In liner higher (PEQ score: 83.1) than either the TSB socket with pin lock liner (PEQ score: 75.94) or the PTB socket with Pelite liner (PEQ score: 63.14) [38]. Participants rated the TSB socket with Seal-In liner highest of all in relation to all satisfaction questions, including prosthetic fit, sitting, walking, walking on uneven ground, stair ascending and descending, suspension, and cosmesis. The TSB socket with pin lock liner was given higher satisfaction scores than the PTB socket with Pelite liner in most questions related to individual satisfaction. Compared with Van de Weg and Van der Windt, participants in Ali et al. represent a younger $(44.02 \pm 6.26 \mathrm{yr})$ and more homogenous group (all trauma-related amputations), whereas participants in Van de Weg and Van der Windt were older $(62.1 \pm 17.5 \mathrm{yr})$ and included amputation due to vascular-related $(37.7 \%)$ and traumatic $(42.3 \%)$ causes.

TSB versus HS. Robust evidence-Selles et al. (DBS 25) reported results from an RCT stating that scorings of PEQ items related to prosthesis satisfaction were not different for the HS ICEX socket compared with the TSB socket [23].

\section{Quality of Life}

Two studies, both having moderate evidence, were found for this outcome [33-34].

TSB. Moderate evidence-Brunelli et al. (DBS 22) reported that there was a significant difference in wellbeing scores between TSB sockets with Seal-in liner (PEQ score: 87 ) and TSB sockets with sleeve suspension (PEQ score: 76) [33]. Participants also scored the ambulation 
and appearance scales higher for the TSB socket with Seal-In liner.

TSB versus PTB. Moderate evidence-Based on results of a study with randomized crossover trial conducted by Coleman et al. (DBS 22), there were no significant differences between TSB sockets with mineral-oil-based elastomeric liner and PTB sockets in the QoL and well-being scores of the PEQ [34].

\section{DISCUSSION}

Nineteen studies summarizing the scientific work of 15 years were reviewed in terms of the effects of transtibial socket designs on various outcomes. Recent studies suggest that outcomes related to the prosthesis and residual limb such as odor, ease of donning and doffing, staining, sweat, skin irritation, and sores seem to depend on the material and/or the type of liner used, but most studies measuring these variables in different liners have a relative short accommodation period with inconsistent results; therefore, firm conclusions cannot be drawn $[30,32-33,35,38]$. Older studies indicate that participants had more perspiration, soreness, creasing, and itching with ICEROSS TSB sockets but the intensity of sweating and itching decreased after a few months [17-18]. More perspiration and skin irritation were reported while participants used a TSB socket with mineral-oil-based elastomeric liner than a PTB socket with Pelite liner [34].

Ease of donning and doffing could be one of the main factors affecting participant satisfaction and preference with the socket type $[41,45]$. Some evidence exists about a positive relationship between satisfaction and ease of donning and doffing with TSB sockets compared with PTB sockets; however, controversy still remains. This could perhaps be due to the diverse liner types and/or different suspension systems used within the different studies. The review revealed that doffing and donning was difficult in TSB sockets with laminated silicone liners [41]. Another study revealed that donning and doffing was better for TSB sockets with polyurethane liners than for ICEROSS and EVA liners [43]. Further, pin lock liners were shown to be easier in donning and doffing than Seal-In liners $[32,35,38]$. In addition, donning and doffing may also be influenced by the suspension system used in a prosthesis, influencing how many steps and trials are required to complete the task.
This review shows a potential benefit of TSB sockets over PTB sockets. Results related to outcome variables such as physical activity and participant preference and satisfaction are similar to, and in some cases better for, TSB sockets than for PTB sockets. The results depend on factors such as participant activity level and age, cause of amputation, residual limb characteristics, interface material, and type of suspension provided by the liner. More active persons or younger users and those with a traumatic cause of amputation appear to benefit from using TSB sockets. Moreover, participants with problems with PTB sockets and those with skin problems or grafts as well as skin tenderness seem to perform better with TSB sockets [17-19,36,38,41]. However, long residual limbs and those with excess soft tissue may not be suitable for TSB sockets $[18,41]$. The rate of skin problems could be lower when participants wear a TSB ICEROSS socket than when wearing a PTB socket [18]. Overall comfort and pain were not reported to be different between TSB and PTB sockets, but comfort experienced during ascending and descending stairs could be higher while using a TSB socket $[18-19,34,36]$. Studies comparing the effect of TSB sockets with different liners indicate that participants with bony residual limbs could benefit from a thicker elastomeric liner. Liners made from polyurethane are generally better accepted than silicone or EVA liners, especially in participants with residual limb pain and skin problems.

Results of studies with weak evidence indicate that active participants with short and pressure-sensitive residual limbs and skin problems could also benefit from VAS sockets [39]. Generally, it was reported that they feel more confident in performing ADLs when using VAS sockets [37]. Although the level of evidence on VAS sockets is not strong enough yet, the results are promising. The observed benefits of the VAS socket could be because of the elevated vacuum and/or the socket shape.

Robust evidence is available demonstrating that elderly persons with amputation ( $>58 \mathrm{yr}$ old) with longtime prosthesis experience $(>13 \mathrm{yr})$ show no difference in physical capability, mobility, satisfaction, experience of pain, or phantom limb pain when using either TSB or Icex HS sockets [23]. The Icex HS socket's shape and volume depends on, among other things, the response of the residual limb soft tissue to the equal pressure applied to it. The shape capturing process for an Icex HS socket is thought to be more objective and thus repeatable than manual shape capturing, but studies on HS sockets are 
relatively scarce and more research is required to validate this concept.

In order to correctly measure the benefit or harm of a socket design, one must consider the characteristics of the participants more systematically. In many of the included studies, factors such as age, activity level, residual limb features, cause and level of amputation, time period between new sockets and old sockets, patient body changes that might result in a poor fit, patient tissue type, and the typical life expectancy of a socket, as well as geographical, social, and cultural aspects, are either neglected or not explored and reported. However, each of these factors (by itself or in combination) can directly or indirectly affect the possible effect of a socket design. We therefore suggest adopting well-defined participant inclusion and exclusion criteria in designing future studies, taking into account as many as possible of the often neglected factors mentioned.

In addition to these factors, experience with a previous socket can also influence the outcomes of a new socket, in particular for patient-reported outcomes. For example, the SCS was higher for participants who were given a socket not different from their previous socket [42]. Moreover, the new and/or different socket is usually connected to higher expectations, a factor that is difficult to control for. Unfortunately, study participants cannot be made blind to socket intervention studies.

Baars and Geertzen and Klute et al. concluded, based on two separate literature reviews on interface liners, that little evidence exists to inform liner prescription [46-47]. Several years have passed since these reviews, but problems persist in regard to clinical guidelines for liner prescription. No measure is available for clinicians to test whether a material for a given liner is the same between the various manufacturers. Variations in the chemical compound can lead to different material properties, although the material is classified under the same name. Material properties can have an effect on outcome variables such as skin irritation and comfort. Some liners incorporate an outer or cover fabric that could influence a liner's mechanical properties. Although some studies report durometer ranges for liners, these ranges are not consistent and thus not comparable between manufacturers. Therefore, some form of standard, universally accepted property measures for liners must be defined and used by the manufacturer for a reliable and valid quantification of liners across manufacturers. Such a measure may include values of viscoelasticity and shock absorption capability of liner materials. For example, Lo et al. developed a set of test methods to quantify mechanical property and thermal comfort variables of materials used in diabetic shoe insole fabrication [48]. These variables included force reduction, compression stress, coefficient of friction, shear, moisture regain, and water vapor transmission. Using a combination of test results, a "performance index" was proposed to categorize materials based on three key clinical and insole user requirements: accommodation, cushioning, and control. A somehow similar quantitative approach could be developed to create a classification system for liners used in prosthetics. With such a classification system, future research could focus on testing associations between variables. For example, testing the quantified mechanical properties of an interface material, together with a given socket design, participant background characteristics, and given residual limb characteristics, could be related to an outcome measure. The obtained results could be used to create a matrix, which in turn could be used as a baseline for socket design and interface material prescription.

Another issue in prosthetic studies is the inconsistency in socket manufacturing and fitting, which makes comparison between socket designs challenging. Product manufacturing consistency is a priority for examining and comparing effects of different designs. Manucharian and Boutwell et al. both stated that the lack of socket shape and volume consistency could adversely affect the results because socket manufacturing relies to a great extent on the prosthetist's skills, knowledge, and past experiences $[31,42]$. These factors, which have a great effect on the socket fit success, are rarely reflected upon and reported by journal articles. Previous studies showed that the socket shape-capturing process (casting) and the subsequent plaster mold rectification lack inter- and intrasocket shape consistency for HS and PTB socket designs but the inconsistencies were less for HS sockets than for the corresponding manually casted and fabricated prosthetic sockets [49-51]. Additionally, the effect of prosthetic alignment also has an effect on socket fit and the related outcomes, such as interface pressure. This stage of prosthesis fitting also lacks consistency due to its subjective nature [52].

Another point this review highlights is the inconsistent socket adaptation time used by many studies ( $n=$ 17). Based on the first author's (M.R.S.) clinical experience and other anecdotal evidence, at least 3 mo seems to be required for a user to adapt to a new socket design, 
especially when he or she changes to TSB or VAS sockets. The existing controversies mentioned in the "Results" section perhaps would have been resolved if researchers had allowed for a longer $(>3 \mathrm{mo})$ socket adaptation period.

Moreover, small sample size, and hence the possible low statistical power associated with it, are another concern with the analyzed studies. RCTs stand at the top of the hierarchy of scientific evidence. However, due to cost and time factors and the relatively small number of eligible participants, RCTs are challenging to conduct in the prosthetics field. One possible alternative study design could be a randomized crossover trial in which participants act as their own controls, therefore reducing confounding covariables. Further, randomized crossover designs are statistically efficient [53]. Conducting randomized crossover studies as multicenter studies would further increase external validity.

\section{CONCLUSIONS}

The included studies have low to moderate methodological rigor. Most studies were conducted on PTB and TSB sockets. From the results, we can concluded that TSB sockets provide greater activity level and prosthesis satisfaction than PTB sockets for active users, those with a traumatic cause of amputation, and younger users. Perspiration and sweating were higher in the TSB socket, but this did not influence satisfaction as much as donning and doffing did. The type of liner used with a TSB socket greatly influences the results of the socket fitting. Therefore, further and especially more systematically conducted studies are recommended in order to explore the influence of liner type on socket fitting.

The HS socket, however, has not been shown to be different from a PTB socket or TSB socket for patientreported outcome measures in older users. However, it has the potential to create a more consistent socket fitting, a variable that greatly influences the successful outcome of prosthetic fitting.

In order to draw a firm conclusion about the benefit or harm of socket designs, and thus provide a base for socket type indication, one must set clear, well-defined participant selection criteria to control variability on the results. To increase methodological rigor, randomized, multicentered crossover study designs could be considered. Furthermore, to provide a scientific basis for pre- scription, comparison of and correlation between mechanical properties of interface material, socket designs, user characteristics, and outcome measures should be measured and reported.

\section{ACKNOWLEDGMENTS}

\section{Author Contributions:}

Study concept and design: M. R. Safari, M. R. Meier.

Acquisition of data: M. R. Safari, M. R. Meier.

Analysis and interpretation of data: M. R. Safari, M. R. Meier.

Critical revision of manuscript for important intellectual content:

M. R. Safari, M. R. Meier.

Financial Disclosures: The authors have declared that no competing interests exist.

Funding/Support: This material was unfunded at the time of manuscript preparation.

\section{REFERENCES}

1. Klute GK, Kantor C, Darrouzet C, Wild H, Wilkinson S, Iveljic S, Creasey G. Lower-limb amputee needs assessment using multistakeholder focus-group approach. J Rehabil Res Dev. 2009;46(3):293-304. [PMID:19675983] http://dx.doi.org/10.1682/JRRD.2008.02.0031

2. Legro MW, Reiber G, del Aguila M, Ajax MJ, Boone DA, Larsen JA, Smith DG, Sangeorzan B. Issues of importance reported by persons with lower limb amputations and prostheses. J Rehabil Res Dev. 1999;36(3):155-63. [PMID:10659798]

3. Klasson B, Buis A. Prosthetic socket fit: Implication of basic engineering principles. In: Simpson D, editor. Advanced prosthetic science, manual 3. Glasgow (United Kingdom): National Centre for Prosthetics and Orthotics, University of Strathclyde; 2006.

4. Hoaglund FT, Jergesen HE, Wilson L, Lamoreux LW, Roberts R. Evaluation of problems and needs of veteran lowerlimb amputees in the San Francisco Bay Area during the period 1977-1980. J Rehabil Res Dev. 1983;20(1):57-71. [PMID:6887067]

5. Hagberg K, Brånemark R, Hägg O. Questionnaire for Persons with a Transfemoral Amputation (Q-TFA): Initial validity and reliability of a new outcome measure. J Rehabil Res Dev. 2004;41(5):695-706. [PMID:15558399] http://dx.doi.org/10.1682/JRRD.2003.11.0167

6. Dillingham TR, Pezzin LE, MacKenzie EJ, Burgess AR. Use and satisfaction with prosthetic devices among persons with trauma-related amputations: A long-term outcome study. Am J Phys Med Rehabil. 2001;80(8):563-71. 


\section{[PMID:11475475]}

http://dx.doi.org/10.1097/00002060-200108000-00003

7. Radcliffe CW. The biomechanics of below-knee prostheses in normal, level, bipedal walking. Artif Limbs. 1962;6(2): 16-24. [PMID:13972953]

8. Staats TB, Lundt J. The UCLA total surface bearing suction below-knee prosthesis. Clin Prosthet Orthot. 1987; 11(3):118-30.

9. Kristinsson O. The ICEROSS concept: A discussion of a philosophy. Prosthet Orthot Int. 1993;17(1):49-55. [PMID:8337100] http://dx.doi.org/10.3109/03093649309164354

10. Patterson S. Editorial: Experiences with negative-pressure socket design [Internet]. The Academy Today. Washington (DC): American Academy of Orthotists \& Prosthetists; 2007. Available from: http://www.oandp.org/ AcademyTODAY/2007Jun/3.asp

11. Emrich R, Slater K. Comparative analysis of below-knee prosthetic socket liner materials. J Med Eng Technol. 1998; 22(2):94-98. [PMID:9597582] http://dx.doi.org/10.3109/03091909809010005

12. Sanders JE, Nicholson BS, Zachariah SG, Cassisi DV, Karchin A, Fergason JR. Testing of elastomeric liners used in limb prosthetics: Classification of 15 products by mechanical performance. J Rehabil Res Dev. 2004;41(2): 175-86. [PMID:15558371] http://dx.doi.org/10.1682/JRRD.2004.02.0175

13. Board WJ, Street GM, Caspers C. A comparison of transtibial amputee suction and vacuum socket conditions. Prosthet Orthot Int. 2001;25(3):202-9. [PMID:11860094] http://dx.doi.org/10.1080/03093640108726603

14. Beil TL, Street GM, Covey SJ. Interface pressures during ambulation using suction and vacuum-assisted prosthetic sockets. J Rehabil Res Dev. 2002;39(6):693-700. [PMID:17943671]

15. Street GM. Vacuum suspension and its effects on the limb. Orthopädie-Technik Quarterly, English Edition. 2006;4.

16. Brunelli S, Averna T, Delusso M, Traballesi M. Vacuum assisted socket system in transtibial amputees: Clinical report. Orthopädie-Technik Quarterly, English Edition. 2009;2.

17. Cluitmans J, Geboers M, Deckers J, Rings F. Experiences with respect to the ICEROSS system for trans-tibial prostheses. Prosthet Orthot Int. 1994;18(2):78-83. [PMID:7991364]

18. Datta D, Vaidya SK, Howitt J, Gopalan L. Outcome of fitting an ICEROSS prosthesis: Views of trans-tibial amputees. Prosthet Orthot Int. 1996;20(2):111-15. [PMID:8876004]

19. Dasgupta AK, McCluskie PJ, Patel VS, Robins L. The performance of the ICEROSS prostheses amongst transtibial amputees with a special reference to the workplace - a pre- liminary study. Icelandic Roll on Silicone Socket. Occup Med (Lond). 1997;47(4):228-36. [PMID:9231496]

http://dx.doi.org/10.1093/occmed/47.4.228

20. McCurdie I, Hanspal R, Nieveen R. ICEROSS - a consensus view: A questionnaire survey of the use of ICEROSS in the United Kingdom. Prosthet Orthot Int. 1997;21(2):124-28. [PMID:9285956]

21. Hachisuka K, Nakamura T, Ohmine S, Shitama H, Shinkoda $\mathrm{K}$. Hygiene problems of residual limb and silicone liners in transtibial amputees wearing the total surface bearing socket. Arch Phys Med Rehabil. 2001;82(9):1286-90.

[PMID:11552206]

http://dx.doi.org/10.1053/apmr.2001.25154

22. Datta D, Harris I, Heller B, Howitt J, Martin R. Gait, cost and time implications for changing from PTB to ICEX sockets. Prosthet Orthot Int. 2004;28(2):115-20. [PMID:15382805] http://dx.doi.org/10.1080/03093640408726696

23. Selles RW, Janssens PJ, Jongenengel CD, Bussmann JB. A randomized controlled trial comparing functional outcome and cost efficiency of a total surface-bearing socket versus a conventional patellar tendon-bearing socket in transtibial amputees. Arch Phys Med Rehabil. 2005;86(1):154-61, quiz 180. [PMID:15641007]

http://dx.doi.org/10.1016/j.apmr.2004.03.036

24. Klute GK, Berge JS, Biggs W, Pongnumkul S, Popovic Z, Curless B. Vacuum-assisted socket suspension compared with pin suspension for lower extremity amputees: Effect on fit, activity, and limb volume. Arch Phys Med Rehabil. 2011;92(10):1570-75. [PMID:21963124] http://dx.doi.org/10.1016/j.apmr.2011.05.019

25. Liberati A, Altman DG, Tetzlaff J, Mulrow C, Gøtzsche PC, Ioannidis JP, Clarke M, Devereaux PJ, Kleijnen J, Moher D. The PRISMA statement for reporting systematic reviews and meta-analyses of studies that evaluate health care interventions: Explanation and elaboration. Ann Intern Med. 2009;151(4):W65-94. [PMID:19622512] http://dx.doi.org/10.7326/0003-4819-151-4-200908180-00136

26. Reeves BC, Deeks JJ, Higgins JP, Wells GA. Including non-randomized studies. In: Higgins JP, Green S, editors. Cochrane handbook for systematic reviews of interventions. Chichester (UK): Wiley-Blackwell; 2008.

27. Downs SH, Black N. The feasibility of creating a checklist for the assessment of the methodological quality both of randomised and non-randomised studies of health care interventions. J Epidemiol Community Health. 1998;52(6): 377-84. [PMID:9764259]

http://dx.doi.org/10.1136/jech.52.6.377

28. Deeks JJ, Dinnes J, D’Amico R, Sowden AJ, Sakarovitch C, Song F, Petticrew M, Altman DG; International Stroke Trial Collaborative Group; European Carotid Surgery Trial Collaborative Group. Evaluating non-randomised intervention 
studies. Health Technol Assess. 2003;7(27):iii-x, 1-173. [PMID:14499048]

http://dx.doi.org/10.3310/hta7270

29. Yiğiter K, Sener G, Bayar K. Comparison of the effects of patellar tendon bearing and total surface bearing sockets on prosthetic fitting and rehabilitation. Prosthet Orthot Int. 2002;26(3):206-12. [PMID:12562067] http://dx.doi.org/10.1080/03093640208726649

30. Ali S, Osman NA, Mortaza N, Eshraghi A, Gholizadeh H, Wan Abas WA. Clinical investigation of the interface pressure in the trans-tibial socket with Dermo and Seal-In X5 liner during walking and their effect on patient satisfaction. Clin Biomech (Bristol, Avon). 2012;27(9):943-48. [PMID:22795863] http://dx.doi.org/10.1016/j.clinbiomech.2012.06.004

31. Boutwell E, Stine R, Hansen A, Tucker K, Gard S. Effect of prosthetic gel liner thickness on gait biomechanics and pressure distribution within the transtibial socket. J Rehabil Res Dev. 2012;49(2):227-40.

[PMID:22773525]

http://dx.doi.org/10.1682/JRRD.2010.06.0121

32. Gholizadeh H, Abu Osman NA, Eshraghi A, Ali S, Sævarsson SK, Wan Abas WA, Pirouzi GH. Transtibial prosthetic suspension: Less pistoning versus easy donning and doffing. J Rehabil Res Dev. 2012;49(9):1321-30.

[PMID:23408214]

http://dx.doi.org/10.1682/JRRD.2011.11.0221

33. Brunelli S, Delussu AS, Paradisi F, Pellegrini R, Traballesi M. A comparison between the suction suspension system and the hypobaric Iceross Seal-In ${ }^{\circledR}$ X5 in transtibial amputees. Prosthet Orthot Int. 2013;37(6):436-44.

[PMID:23436696]

http://dx.doi.org/10.1177/0309364613476531

34. Coleman KL, Boone DA, Laing LS, Mathews DE, Smith DG. Quantification of prosthetic outcomes: Elastomeric gel liner with locking pin suspension versus polyethylene foam liner with neoprene sleeve suspension. J Rehabil Res Dev. 2004;41(4):591-602.

[PMID:15558387]

http://dx.doi.org/10.1682/JRRD.2004.04.0591

35. Eshraghi A, Abu Osman NA, Karimi MT, Gholizadeh H, Ali S, Wan Abas WA. Quantitative and qualitative comparison of a new prosthetic suspension system with two existing suspension systems for lower limb amputees. Am J Phys Med Rehabil. 2012;91(12):1028-38. [PMID:23168378] http://dx.doi.org/10.1097/PHM.0b013e318269d82a

36. Van de Weg FB, Van der Windt DA. A questionnaire survey of the effect of different interface types on patient satisfaction and perceived problems among trans-tibial amputees. Prosthet Orthot Int. 2005;29(3):231-39.

[PMID:16466153]

http://dx.doi.org/10.1080/03093640500199679
37. Ferraro CB. Outcomes study of transtibial amputees using elevated vacuum suspension in comparison with pin suspension. J Prosthet Orthot. 2011;23(2):78-81.

http://dx.doi.org/10.1097/JPO.0b013e3182173b83

38. Ali S, Abu Osman NA, Naqshbandi MM, Eshraghi A, Kamyab M, Gholizadeh H. Qualitative study of prosthetic suspension systems on transtibial amputees' satisfaction and perceived problems with their prosthetic devices. Arch Phys Med Rehabil. 2012;93(11):1919-23.

[PMID:22579945]

http://dx.doi.org/10.1016/j.apmr.2012.04.024

39. Sutton E, Hoskins RB, Fosnight T. Using elevated vacuum to improve functional outcomes: A case report. J Prosthet Orthot. 2011;23(4):184-89. http://dx.doi.org/10.1097/JPO.0b013e3182346975

40. Gholizadeh H, Abu Osman NA, Kamyab M, Eshraghi A, Lúvíksdóttir AG, Wan Abas WA. Clinical evaluation of two prosthetic suspension systems in a bilateral transtibial amputee. Am J Phys Med Rehabil. 2012;91(10):894-98. [PMID:22173083]

http://dx.doi.org/10.1097/PHM.0b013e31823c74d7

41. Hachisuka K, Dozono K, Ogata H, Ohmine S, Shitama H, Shinkoda K. Total surface bearing below-knee prosthesis: Advantages, disadvantages, and clinical implications. Arch Phys Med Rehabil. 1998;79(7):783-89. [PMID:9685091] http://dx.doi.org/10.1016/S0003-9993(98)90356-2

42. Manucharian SR. An investigation of comfort level trend differences between the hands-on patellar tendon bearing and hands-off hydrocast transtibial prosthetic sockets. J Prosthet Orthot. 2011;23(3):124-40. http://dx.doi.org/10.1097/JPO.0b013e3182248bf2

43. Aström I, Stenström A. Effect on gait and socket comfort in unilateral trans-tibial amputees after exchange to a polyurethane concept. Prosthet Orthot Int. 2004;28(1):28-36. [PMID:15171575]

44. Owens DK, Lohr KN, Atkins D, Treadwell JR, Reston JT, Bass EB, Chang S, Helfand M. AHRQ series paper 5: Grading the strength of a body of evidence when comparing medical interventions - agency for healthcare research and quality and the effective health-care program. J Clin Epidemiol. 2010;63(5):513-23. [PMID:19595577] http://dx.doi.org/10.1016/j.jclinepi.2009.03.009

45. Boonstra AM, van Duin W, Eisma W. Silicone suction socket (3S) versus supracondylar PTB prosthesis with Pelite liner: Transtibial amputees' preferences. J Prosthet Orthot. 1996;8(3):96-99.

http://dx.doi.org/10.1097/00008526-199600830-00006

46. Baars EC, Geertzen JH. Literature review of the possible advantages of silicon liner socket use in trans-tibial prostheses. Prosthet Orthot Int. 2005;29(1):27-37.

[PMID:16180375]

http://dx.doi.org/10.1080/17461550500069612 
47. Klute GK, Glaister BC, Berge JS. Prosthetic liners for lower limb amputees: A review of the literature. Prosthet Orthot Int. 2010;34(2):146-53. [PMID:20384553] http://dx.doi.org/10.3109/03093641003645528

48. Lo WT, Yick KL, Ng SP, Yip J. New methods for evaluating physical and thermal comfort properties of orthotic materials used in insoles for patients with diabetes. J Rehabil Res Dev. 2014;51(2):311-24. [PMID:24933729] http://dx.doi.org/10.1682/JRRD.2013.01.0012

49. Buis AW, Blair A, Convery P, Sockalingam S, McHugh B. Pilot study: data-capturing consistency of two trans-tibial casting concepts, using a manikin stump model: a comparison between the hands-on PTB and hands-off ICECAST compact concepts. Prosthet Orthot Int. 2003;27(2):100-106. [PMID:14571939] http://dx.doi.org/10.1080/03093640308726665

50. Convery P, Buis AW, Wilkie R, Sockalingam S, Blair A, McHugh B. Measurement of the consistency of patellartendon-bearing cast rectification. Prosthet Orthot Int. 2003; 27(3):207-13. [PMID:14727701] http://dx.doi.org/10.1080/03093640308726683

51. Safari MR, Rowe P, McFadyen A, Buis A. Hands-off and hands-on casting consistency of amputee below knee sockets using magnetic resonance imaging. ScientificWorldJournal. 2013;2013:486146. [PMID:24348167] http://dx.doi.org/10.1155/2013/486146
52. Neumann ES. State-of-the-science review of transtibial prosthesis alignment perturbation. J Prosthet Orthot. 2009; 21(4):175-93. http://dx.doi.org/10.1097/JPO.0b013e3181baaa68

53. Stufken J. Optimal crossover designs. In: Ghosh S, Rao CR, editors. Handbook of statistics: Design of analysis and experiments. Vol. 13. Amsterdam (the Netherlands): Elsevier; 1996. p. 63-90.

Submitted for publication August 13, 2014. Accepted in revised form April 23, 2015.

This article and any supplementary material should be cited as follows:

Safari MR, Meier MR. Systematic review of effects of current transtibial prosthetic socket designs-Part 1: Qualitative outcomes. J Rehabil Res Dev. 2015;52(5): 491-508.

http://dx.doi.org/10.1682/JRRD.2014.08.0183

ResearcherID: Mohammad Reza Safari, PhD: I-55322014; Margrit Regula Meier, PhD: I-5388-2015

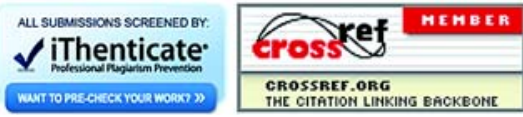

